\title{
Democracia e participação social, um problema geográfico? A contribuição de conselhos municipais para a democratizaçãa do poder e do espaço
}

\section{Democracy and social participation, is it a geagraphical problem? The contribution of municipal councils for the democratization of power and space.}

\section{Resumo:}

Conselhos Municipais têm adquirido destaque no Brasil, após a Constituição de 1988 ter elegido o paradigma participativo como um princípio constitucional e político, colocando-o no âmago do processo de consolidação da democracia. A partir de um estudo empírico, avaliam-se esses recursos institucionais de participação e o processo de institucionalização de Conselhos no município de Salvador, Brasil. Discute-se, também, a relação entre democracia e Geografia, além de chamar atenção para mudanças operadas na estrutura do poder político-administrativo pós-Constituição de 1988 e apontar o que faz da participação um problema geográfico. Constatou-se que, mesmo em um contexto adverso à participação, avanços foram alcançados na institucionalização e regulamentação da participação social no espaço político local, todavia, o sucesso e, ao mesmo tempo, o não êxito na atuação de alguns dos Conselhos Municipais estudados constituem uma mesma realidade.

\begin{abstract}
:
Municipal Councils have gained prominence in Brazil, after the 1988 Federal Constitution stablished the participatory paradigm as a constitutional and political principle, placing it at the core of the process of consolidating democracy. Based on empirical search, this study evaluates these institutional resources of participation and the process of institutionalization of councils in the city of Salvador, Brazil. It is also discussed the relationship between democracy and geography, in addition to drawing attention to changes in the political-administrative power structure post-Constitution of 1988, and points out what makes participation a geographical problem. It was found that, even in an adverse context for participation, advances were achieved in the institutionalization and regulation of social participation in the local political space. However, success of ones at the same time others failures constitute the reality of Municipal Councils performance.
\end{abstract}

* Doutorando no Programa
de Pós-graduação em Geogra-
fia (PPGG), da Universidade
Federal do Rio de Janeiro; é
geógrafo, licenciado e mestre
em Geografia pela Universida-
de Federal da Bahia (UFBA)-
UniversidadeFederal da Bahia,
Instituto de Geociências

Palavras-chave:

Conselhos municipais;

Democratização; Institucionalização;

Participação social;

Recursos institucionais;

Keywords:

Social participation; Municipal councils;

Democratisation; Institucional resources; Institutionalization. 


\section{INTRODUÇÃO}

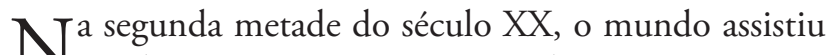
àquilo que Huntington (1994) denominou como a "terceira onda de democratização". Essa transição política, pela qual passaram inúmeros países no último quartel do século passado, foi iniciada pelos países do sudoeste da Europa, depois atingiu a América Latina, passou por todo o leste Europeu até alcançar a Ásia, promovendo, de acordo com Sola (1999), importantes transformaçôes na ordem política do mundo.

Essas transfigurações são evidências empíricas das dinâmicas e mudanças sociais do mundo contemporâneo, cuja repercussão e prolongamento se manifestam no presente contexto socioespacial. Esse processo de expansão do regime democrático não se deu sem efeitos para as práticas espaciais, pois promoveu o (res)surgimento de novos agentes sociais, agentes coletivos que atuam em rede na escala mundo (SOYER; BLÄSER, 2009), fortaleceu a ação de determinados (agentes) em detrimento de outros, enfim, transformou a dinâmica social e os fenômenos políticos deste século.

Nesse sentido, considera-se a tendência mundial de ascensão de regimes democráticos de governo como um marco de mudança de paradigma para a Geografia $\left(\right.$ BUSSI, 2007a) ${ }^{1}$. Offe (1999) se refere ao fenômeno da democratização como a mudança social mais abrangente ocorrida até o final dos anos de 1990, reforçando a ideia de que esse processo aconteceu no nível da ordem política.

Novas dinâmicas territoriais emergiram junto com o propalado processo de globalização, de reformas institucionais do Estado e de transição política. Todos esses acontecimentos corroboram a ideia de que grandes transformaçóes - de ordem política, cultural, econômico, social e natural - ocorreram ou estão em curso na história recente do mundo.

No Brasil, a transição e a promulgação da Constituição Federal de 1988 (CF/1988) fizeram do paradigma participativo um princípio constitucional e político, colocando-o no âmago do processo de consolidaçáo da democracia no país. O fato é que o Brasil pós-1988 se tornou referência em instrumentos jurídico-normativos que garantem o direito à participação da sociedade civil no planejamento e na gestão de políticas públicas.

Desde então, canais de diálogo entre Estado e sociedade civil organizada estão sendo construídos e arenas e espaços políticos participativos se constituem em recursos institucionais capazes de estabelecer uma nova maneira de tomar decisão. Essas mudanças sociais implicam necessariamente novas práticas espaciais (sociais e territoriais), convidando os geógrafos a refletir sobre as relaçóes entre Geografia e democracia.

Essa reflexão passa pela compreensão de que o espaço é uma categoria fundamental para a análise das sociedades, pois é "suporte para a vida em sociedade e, ao mesmo tempo, um condicionador dos projetos humanos, um referencial simbólico, afetivo e, também, para a organizaçáo política uma arena de luta" (SOUZA, 1996, p. 11).

A política constitui sua essência, uma vez que é arena de conflitos e, como tal, é esfera da pluralidade humana, da diferença, da possibilidade da heterogeneidade de trajetórias com distintas vozes e da coexistência conflituosa entre os indivíduos (MASSEY, 2008). Espaço e política sáo assim coconstitutivos e estruturadores da realidade social e, portanto, indissociáveis dos processos sociais (BORGES, 2015a).

$\mathrm{O}$ desafio posto foi aceito. Assim, aqui serão tratadas algumas das razóes que fazem da democracia e da participação social, enquanto práticas sociais, problemas com uma forte dimensão espacial, logo, passíveis de serem abordados pela Geografia. Primeiro, parte-se da premissa básica de que a democracia, na condição de modelo político e prática social, é afetada pelos atributos e constrangimentos espaciais (CASTRO, 2013; 2011). Paralelamente a esse pensamento, considera-se que os processos participativos inaugurados pelas inovaçóes democráticas também tenham natureza espacial.

Os impactos promovidos pelas inovaçôes democráticas estabelecidas na Constituição de 1988 também são problematizados, apontando para a criação de novos espaços institucionais e para o papel de protagonista que o município brasileiro assume nesse processo de mudança institucional.

O novo ente federativo surge como um espaço político-institucional (CASTRO, 2003) ou um território institucionalizado (FONSECA, 2003). Este território, o município, é o "espaço de aprendizagem e exercício da cidadania e aprimoramento da democracia" (BORGES, 2015, p. 26).

Nele, o indivíduo adquire o status formal de cidadáo, pode exercer seus direitos políticos (votar e ser votado), sendo nessa escala que as políticas públicas e governamentais ou territoriais se materializam, também, é nela que há a maior possibilidade de o cidadão pressionar seus representantes políticos e participar, de modo ativo, da discussão e da gestáo da coisa pública. Em outros termos, é nesse território que ocorre a distribuição substantiva do "pacote de direitos, obrigaçóes e práticas vinculadas à afiliação [cidadâ]"2.

Para além desses argumentos teóricos, também 
serão apresentados os resultados de um estudo empírico sobre a institucionalização da participação social em Salvador e o papel desempenhado pelos Conselhos Municipais nos espaços políticos locais. Antes, discute-se a relação existente entre democracia e Geografia, além de chamar atençáo para mudanças operadas na estrutura do poder político-administrativo e as implicaçóes ocorridas no território nacional, para depois apontar o que faz da participação social um problema geográfico.

\section{DEMOCRACIA: UM PROBLEMA QUE SE IMPÓE Å GEOGRAFIA}

[...] não há como pensar a geografia sem a política, e fazê-lo é empobrecê-la (CASTRO, 2006, p. 51).

[...] a democracia é a política em sua forma mais plena (CASTRO; RODRIGUES; RIBEIRO, 2013, p. 12).

No texto intitulado Geógraphie, démocratie et participation: explication d'une distance, arguments pour un rapprochement, publicado em 2001, o geógrafo francês Michel Bussi acredita que haja uma falta de interesse por parte dos geógrafos franceses para com a democracia e temas correlatos a ela, como o da participação. Para o autor, há uma relação visceral entre democracia, Geografia e política. Considerando esse pressuposto, Bussi (2001) defende uma aproximação entre a disciplina e as questóes da democracia, isto é, a incorporação do debate teórico e da prática relacionada a essa forma de governo, à agenda da disciplina.

Bussi $(2007 \mathrm{a}$; 2007b) propóe uma geografia da democracia, que se aproxima em muito daquilo que Bläser e Soyer (2009) denominam de uma geografia da sociedade civil. Tanto o geógrafo francês quanto os alemães estão de acordo quanto às implicaçôes espaciais da intensa difusão/retomada da democracia pelo mundo, a partir do final do século XX.

A tendência mundial, iniciada no século passado, de ascensão de regimes democráticos de governo é o marco maior da mudança de paradigma para a Geografia. Esses processos de transição política representaram a passagem de uma lógica de dominação para uma de negociação dos conflitos (BUSSI, 2007a, s.p).

Para Bussi (2007b, s.p), a difusão da democracia e dos seus valores "é uma questão fundamental no mundo contemporâneo", o que lhe permite defender uma Geografia atenta às relaçóes entre democracia representativa e territórios; uma Geografia que considere a "evolução da política (constituição, sistema partidário, divisōes administrativas, voto, sondagem de opiniâo,
etc.)"(BUSSI 2007b, s.p).

Entre 1979 e 1990, diversos países da América Latina, entre eles o Brasil, passaram por um processo que ficou conhecido como transiçâo democrática ${ }^{3}$. A retomada da democracia eleitoral e dos direitos civis e políticos significou a instauraçâo de uma nova ordem política que, por sua vez, pôs em prática novos valores e condutas (BUSSI, 2003; 2007b; WANIEZ et al. 2003).

Essa mudança de regime representou a emergência de novos agentes políticos, além da transformação nas relaçôes políticas, sociais e o estabelecimento de novas maneiras de o Estado e a sociedade civil se relacionarem.

No Brasil, a redemocratização recente do país promoveu inovaçóes institucionais em todas as esferas de governo, conferiu hodiernos papéis à sociedade civil e criou outro cenário político no país (RÜCKERT, 2005), em que as instituiçôes participativas passaram a ter certo protagonismo.

A institucionalização da participação política e o reconhecimento dos direitos cidadãos e da inclusão da sociedade civil nos círculos de poder se firmam como novas condutas sociais e práticas políticas, com o objetivo de dar maior substância e legitimidade à democracia representativa brasileira.

A CF/1988 instituiu a criação de uma estrutura participativa que passou a permitir a ação política institucionalizada da sociedade civil na definição das políticas públicas locais: orçamentos participativos, fóruns, conferências, planos diretores de desenvolvimento urbano (PDDU) e conselhos municipais de políticas. Esses últimos, objeto de estudo deste trabalho, são desdobramentos de experiências colegiadas de Conselhos iniciados no contexto do regime militar brasileiro. Todavia, surgiram como uma grande novidade legal na presente Carta Constituinte de 1988. Configuram-se, desde então, como espaços político-institucionais de participaçáo social na gestáo municipal, responsáveis por fiscalizar, propor e definir políticas públicas nas esferas locais.

Em tese, os Conselhos são um dos principais elementos de inovação do cenário político nacional, pois representam espaços legítimos de expressão de interesses, mediação de conflitos e construção de consensos e controle social. Portanto, são espaços de negociação entre governos e sociedade civil organizada no que tange à condução das políticas públicas municipais.

É vasta a literatura acadêmica produzida no âmbito nacional, nos últimos anos, sobre esses recursos institucionais, o paradigma participativo e as práticas desenvolvidas no Brasil. No entanto, a discussão espacial é negligenciada em grande parte dos trabalhos. Espaço, 
política e democracia se consubstanciam e, portanto, são indissociáveis, o que permite afirmar que o problema da participação social é também geográfico (BORGES, 2015b).

Observa-se que, em muitos estudos, as análises deixam escapar um problema real em relação à base territorial de representação dos discursos. Do mesmo modo, esquece-se que os Conselhos, pelo menos alguns deles, são instrumentos de intervenção no espaço, na medida em que o exercício de representaçáo dos diferentes e conflitantes interesses - em especial aqueles acenados pelas entidades, organizações sociais, sindicatos e pelo setor produtivo - se revela em disputas de poder que se materializam no território. Desse modo, grande parte das análises desenvolvidas por sociólogos, cientistas sociais ou políticos peca por omitir a dimensão espacial dos processos políticos.

De modo geral, as reflexóes se esquivam do fato de que as reivindicaçóes, as demandas dos grupos de interesses são setorizadas e, em alguns casos, fragmentadas, uma vez que as açôes, as práticas sociais, as vozes e o teor dos discursos estão alicerçados em diferentes lugares e territórios do espaço político. A relação entre democracia e escala também precisa ser explicitada. O recorte espacial, a dimensão territorial e o tamanho populacional são desconsiderados pela maioria dos pesquisadores. Faltam estudos comparativos sobre a participação social em municípios de diferentes dimensões e com taxas de urbanização distintas, por exemplo.

Diante dessas ideias introdutórias, é importante destacar as implicaçóes que o rearranjo nas estruturas políticas em voga no território brasileiro pós-Constituição de 1988, caracterizado pelo fortalecimento das estruturas de gestão local, tem exercido sobre a organização dos espaços políticos locais, em especial no que tange à garantia de direitos, ao acesso a serviços públicos de qualidade e à promoçáo de equidade socioespacial ${ }^{4} \mathrm{e}$ de bem-estar social coletivo.

\subsection{Inovaçóes democráticas no Brasil: novos agentes, novos espaços, novos processos políticos}

É fato que a Constituição Cidadã (1988) representou, tanto em termos normativos quanto práticos, uma mudança nos processos de organização do território nacional. A Carta Magna ocasionou profundas inovaçôes institucionais, a exemplo da descentralização e da "autonomia" política, administrativa e "financeira" dos estados e municípios, reconhecendo-os como entes da federação com plenos direitos (BORGES, 2015b).

A CF/1988 consagrou um novo pacto social
(RÜCKERT, 2005), isto é, refundou a relação clássica entre Estado e sociedade civil, além de ter fortalecido os novos recortes territoriais subnacionais e os espaços de ação política, o que, sem dúvida, foi crucial para os processos de formulação de políticas públicas e de decisão governamental.

Também significou a convergência de um projeto democrático-participativo que garantiu a participação política como um direito constitucional legítimo e redefiniu os papéis da sociedade civil e sua relação com o Estado na condução de determinadas políticas. Desde entâo, deu-se início a um processo de criação e institucionalizaçâo de uma arquitetura participativa em todas as esferas de governo, em especial, nas escalas locais, a exemplo dos Orçamentos Participativos e Conselhos Municipais.

A descentralização político-administrativa foi vista como uma necessidade fundamental para a redemocratização do país e, portanto, para a democratizaçáo de bens e serviços públicos e promoção de maior eficiência à gestão das políticas públicas locais. Afinal, o município passou a ser reconhecido como espaço político legítimo do conflito, do acordo, da cooperação e da negociaçáo; arena capaz de promover uma proximidade entre governantes e governados. Nessa arena, a populaçáo local teria melhores possibilidades e maiores facilidades para dar visibilidade a suas demandas.

Ocorreu, assim, a elevação da escala política local ao status de espaço da cidadania, uma vez que o município se tornou uma "estrutura de gestão importante na definição de normas e implantaçấo de políticas públicas" (RODRIGUES, 2014, p.160).

O município é, deste modo, considerado o ente territorial e a escala geográfica mais adequada à aplicação de determinadas tipologias de serviços públicos essenciais à realização da cidadania. De acordo com Castro (2003, p. 17; 2010), é uma escala na qual "a atuação do poder público é mais visível, tanto em relação à disponibilidade do aparato institucional para a oferta de políticas públicas direcionadas para a população residente como em relação a seus resultados".

$\mathrm{Na}$ opinião de Barbosa (2010, s.p), a descentralizaçáo significou a realização da democratização em termos práticos e concretos, isto é, "substancializar a democracia na vida cotidiana”. É nesse sentido que, para o autor, a proposta de mudança democrática defendida pelos movimentos sociais e por partidos opositores ao regime militar tinha na esfera municipal o "lócus privilegiado da ação pública como garantia de atendimento das demandas sociais"(BARBOSA, 2010, s.p). 
Os rearranjos nas estruturas políticas e espaciais promovidos pela Constituição/1988, com o fortalecimento das escalas decisórias locais, redesenharam o modo de concepção e formulação das políticas públicas, culminando em um processo de municipalização setorial e de segmentos especiais, bem como no fortalecimento das relaçốes entre os diferentes níveis de governo e de articulação de escalas na formulação e implantação dessas políticas.

Se a descentralização significou o mesmo que o rompimento com as estruturas de poder extremamente centralizadas, a redemocratização do Estado brasileiro e da sociedade civil, através da Constituiçâo de 1988, definiu novas regras e estabeleceu canais institucionais de interlocução entre ambos, além de fazer da prática participativa uma condiçâo fundamental para a transferência de recursos financeiros federais para os níveis subnacionais de governo (CORTES, 2011).

A participação política se estabeleceu como princípio norteador para os processos decisórios, algo essencial para a consolidação da democracia no país. Desde então, em especial a partir da década de 1990, há um movimento crescente de "formação de uma vasta institucionalidade participativa, que inclui conselhos, [...], entre outras formas de participação"(AVRITZER, 2011, p. 13).

Em consonância com as ideias acima, concorda-se com Castro (2004, s.p), quando ela diz que:

[...] a descentralizaçáo tem fortalecido, mesmo se de forma bastante diferenciada e no geral ainda precária, a pluraridade dos atores sociais que participam da cena pública. Este processo vem propiciando o surgimento e o fortalecimento de instituiçóes de participação da sociedade civil local e de cooperação interinstitucional, conferindo maior visibilidade aos marcos territoriais da participação e da cooperação.

Os espaços políticos de participação social Conselhos Municipais - e a sociedade civil, por meio de organizaçóes sociais, representam um importante potencial capaz de influenciar os processos decisórios governamentais, a formulação das políticas públicas e, em alguns casos, a alocação de recursos públicos.

Nesse contexto político contemporâneo, o Brasil tem se tornado um campo fértil para as iniciativas que póem em prática processos de construção coletiva de políticas públicas. Assim, há de se concordar com Rodrigues (2014), para quem, nas democracias, esses processos devem ter como alicerce a manifestação permanente da sociedade civil, o que envolve os recursos institucionais e os recortes dos espaços da participação política.
Dessa maneira, é extremamente relevante refletir se e como as populaçôes locais se apropriam das inovaçōes institucionais participativas. Afinal, para organizar seus espaços políticos, esses canais democráticos são favoráveis ao fortalecimento da democracia em escala local? Em outros termos, eles contribuem para a melhoria e a democratizaçáo dos processos de planejamento e gestão de políticas públicas?

Responder a essas interrogaçóes exige que se considere o contexto social, econômico e cultural local como elementos importantes na análise dos Conselhos Municipais como inovaçôes, visto que o contexto social afeta a performance das instituiçôes, como mostrou Putnam (1996).

Nessa linha de pensamento, Lüchmann (2009) acrescenta ao dizer que os fatores impeditivos de processos participativos são complexos e envolvem questôes de natureza política, econômica, social e cultural, e dizem respeito "a uma sociedade estruturalmente assentada sobre os pilares do clientelismo, do autoritarismo e das desigualdades sociais" (LÜCHMANN, 2009, s.p).

Desse modo, o fenômeno da participação institucional será avaliado pela associaçáo de aportes teóricos da Sociologia Política, da Ciência Política e da geografia, no sentido de contribuir, ainda que minimamente, para o entendimento da complexidade do objeto estudado.

\section{A PARTICIPAÇÁO SOCIAL NO BRASIL: CONSELHOS MUNICIPAIS COMO RECUR- SOS INSTITUCIONAIS A SERVIÇO DA DE- MOCRATIZAÇÁO DO PODER E DO ESPA- ÇO}

O Brasil, nos últimos anos, se tornou referência mundial em termos de inovaçóes democráticas e difusão de uma institucionalidade participativa (AVRITZER, 2011; LAVALLE, 2011), isto é, arenas de negociação, ação política, decisão e controle social, erigidas sobre o princípio de democratização do planejamento e da gestão de políticas públicas, com enorme potencial de contribuir para uma maior eficiência e efetividade administrativa e promoção de equidade socioespacial (BORGES, 2014).

Promulgada em 1988, a Constituição Federal também foi batizada como Constituiçáo Cidadã, sendo considerada o marco definidor legal da redemocratizaçáo recente do país, pois reinstituiu os direitos políticos suspensos pelo regime militar e promoveu o reconhecimento e a ampliação de direitos cidadãos até então inexistentes.

A CF/1988 deu início a uma transformaçáo na relaçáo estabelecida entre sociedade civil e Estado. Essa relação passou a ser mediada por espaços participati- 
vos de inclusão das aspiraçôes e demandas sociais nos processos decisórios governamentais, além de garantir a participação social como um direito constitucional legítimo por meio de inovaçóes democráticas que possibilitaram o surgimento de novos agentes e novas instituições políticas.

Buvinich (2014) chama atenção para um parêntese extremamente necessário a ser feito quanto à obrigatoriedade de implantação de Conselhos Muni- cipais. A autora salienta que, embora muitos pesquisadores levem a crer que a formação da maioria dos Conselhos seja obrigatória, segundo a Constituição, na prática, a CF/1988 estabelece a participação social como uma diretriz e remete a leis específicas o papel de regulamentação dos dispositivos contitucionais. A Figura 1 mostra que, entre os nove Conselhos Municipais com os maiores percentuais de implantaçáo no Brasil até 2012, oito deles (exceto o Conselho de Educaçáo) são regula-

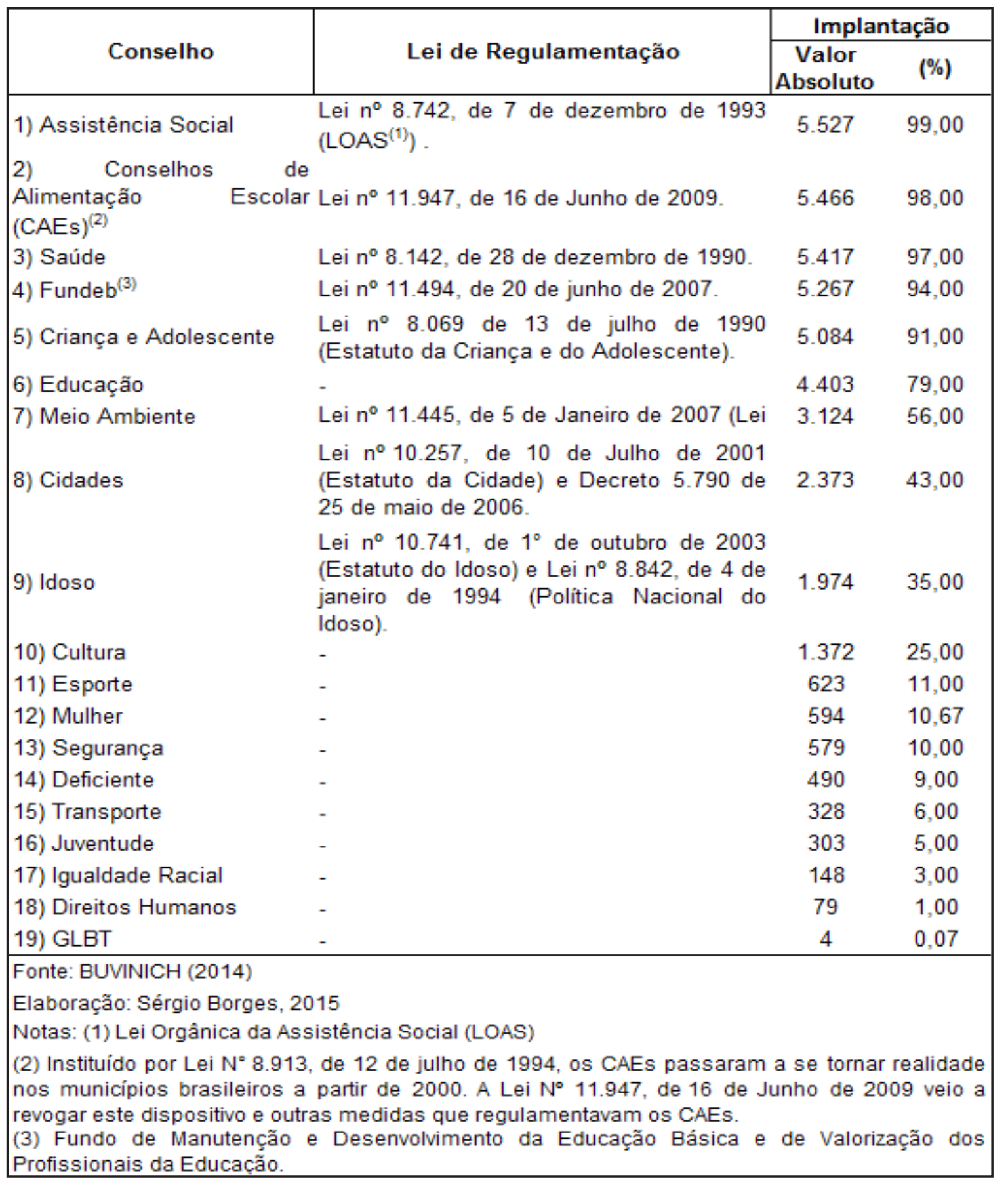

Figura 1 - Conselhos Municipais com maior percentual de implantação no Brasil - 2012

Fonte: Elaborado com base em Buvinich (2014) e de levantamento realizado pelo próprio autor. 


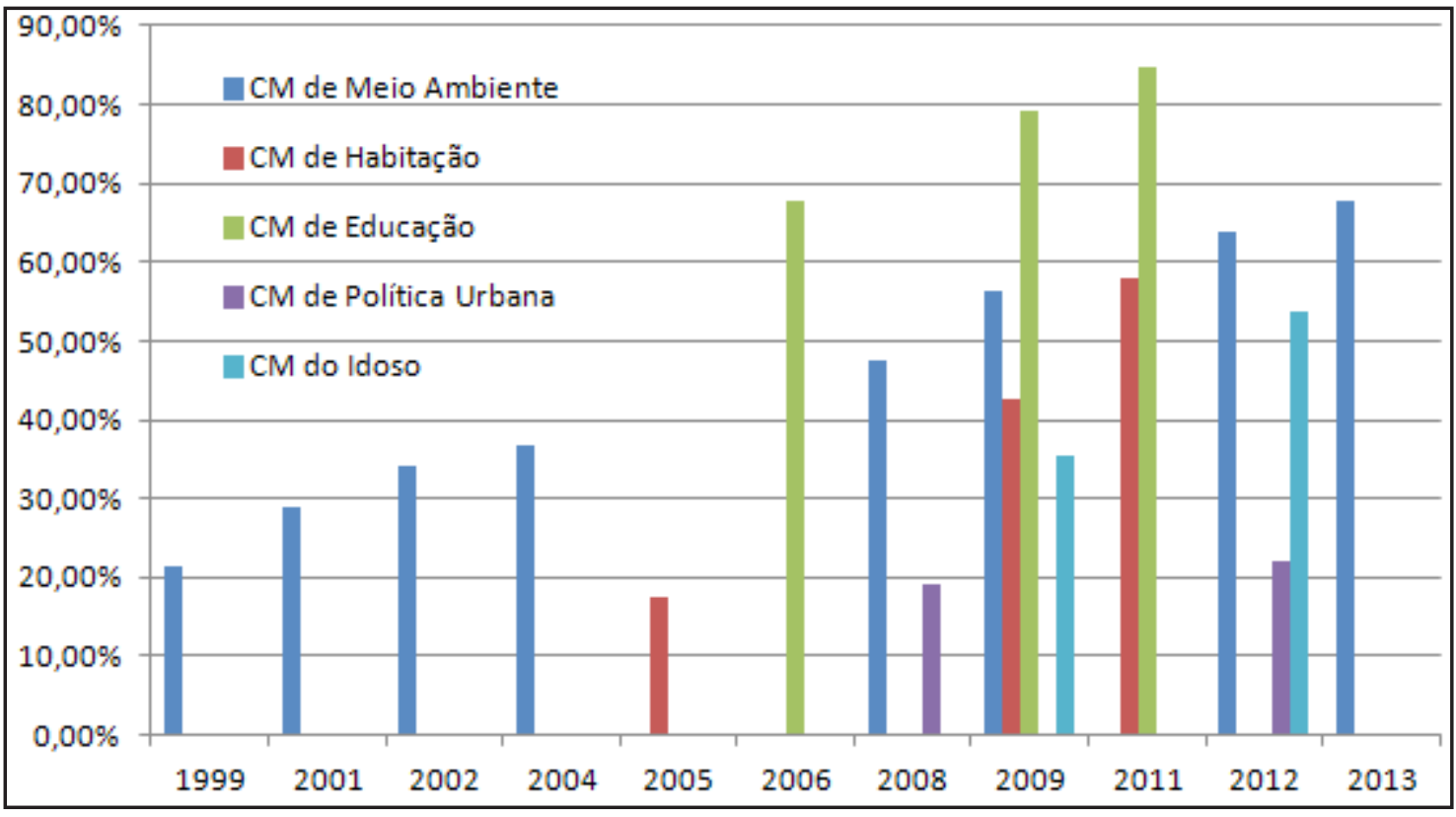

Figura 2 - Conselhos Municipais no Brasil - 1999-2013

Fonte: IBGE, Pesquisa de Informaçóes Básicas Municipais

Elaboração: Próprio autor.

mentados por lei.

Após a promulgação da Constituição Cidadã, propalou-se um movimento de criaçáo de Conselhos em todas as esferas de governo e no campo das várias políticas setoriais e de segmentos especiais. Isso faz do cenário político recente do país um campo fértil para estudos empíricos que busquem compreender a realidade criada por esses espaços democráticos.

Em todas as Pesquisas de Informaçôes Básicas Municipais (MUNIC), divulgadas pelo Instituto Brasileiro de Geografia e Estatística (IBGE), houve aumento expressivo e, em alguns casos, contínuo, no movimento de criação de Conselhos Municipais (CM), como se pode notar na Figura 2.

\section{CONSELHOS MUNICIPAIS, PARTICIPA- ÇÁO SOCIAL E DEMOCRATIZAÇÃO DA ĢESTÂO PÚBLICA LOCAL}

Milani (2006), em texto dedicado à relação entre políticas públicas locais e participação, lembra que, em meados dos anos 1980, surgiu um dilema entre a "necessidade de políticas públicas efetivas versus garantia de controles democráticos" (p.180). O problema posto girava em torno da confiança (ou da falta dela) nos representantes políticos e do controle e eficiência da burocracia.

Ainda de acordo com o autor, modelos foram

pensados como artifícios para enfrentar esse dilema, como, por exemplo, a combinação de:

[...] estratégias de descentralização, a adoção de mecanismos de responsabilização dos gestores públicos (responsiveness e accountability), a gestão por resultados, o incremento do controle social, além de dispositivos de participaçáo social que visam a envolver cidadáos e organizaçôes da sociedade civil na gestáo pública (MILANI, 2006, p. 180, Grifos Nosso).

Em complemento à ideia de Milani (2006), vale lembrar que a crise do modelo burocrático de administraçáo pública se revelou por meio de um padrão centralizador, excludente e discricionário. Modelo esse que não atendia de modo satisfatório às demandas por políticas públicas geradas pela populaçáo local, levando ao questionamento da "legitimidade do Estado como ator e arena política do processo decisório” (MILANI, 2006, p.182).

Eficiência, eficácia e efetividade das ações governamentais tornaram-se palavras de ordem para gestores e administradores públicos, em paralelo, a inclusão da participação dos cidadãos e de organizaçóes representativas da sociedade civil no processo de planejamento e gestão de políticas públicas adquiriu cada vez mais um destaque maior.

Em relação a esse debate, Gohn (2006) acredita que os Conselhos Municipais sejam dotados de um potencial de transformação política, desde que sejam efetivamente representativos das demandas sociais por políticas setoriais e de segmentos específicos. Se assim for, 
devem ter a capacidade de imprimir um novo formato a essas políticas, pois estáo relacionados aos processos de formulação e de tomada de decisões e, acrescente-se, de controle e fiscalização.

É por compartilhar dessa perspectiva que os espaços participativos são considerados uma via possível para romper com o padrão centralizador, tecnocrático, discricionário, corrupto e ineficiente de gestâo das políticas públicas locais, que predomina em muito dos municípios brasileiros.

Pensa-se que instituir e incluir a participação de entidades e organizaçóes sociais representativas da sociedade civil nos círculos de decisão possa ser de extrema relevância tanto para a organização quanto para a oferta e os resultados das políticas públicas.

Nesse sentido, promover a participação social no planejamento e na gestáo municipais contribuirá para a efetiva democratização do acesso da populaçáo local às políticas públicas e, por sua vez, ao exercício pleno da cidadania, já que, em tese, a inclusão dos cidadãos nos círculos de poder deverá conferir maior legitimidade aos processos decisórios e à implantaçâo das decisóes.

Vale ressaltar que os avanços jurídicos representados pela Constituição e outras leis ou proposições, a exemplo do Estatuto da Cidade (Lei no 10.257/2001), por si só não promoverão mudança radical no cenário político do país e nem resolverão os históricos problemas estruturais e sociais. Porém, a existência de uma legislação forte é de suma importância para a obtenção de avanços e conquistas sociais.

Em sintonia com o exposto, Carvalho (2014, p.14-15) ajuda a perceber que o fenômeno da cidadania é complexo e historicamente definido. Para ele,

\footnotetext{
O exercício de certos direitos, como a liberdade de pensamento e o voto, não gera automaticamente o gozo de outros, como a segurança e o emprego. $\mathrm{O}$ exercício do voto não garante a existência de governos atentos aos problemas básicos da população. Dito de outra maneira: a liberdade e a participação não levam automaticamente, ou rapidamente à resolução de problemas sociais.
}

No entanto, a lei é um fator estruturador das práticas sociais e, ao mesmo tempo, reflexo dessas práticas sociopolíticas. Em trabalho recente, Magdaleno (2013) discute a relação visceral existente entre marcos legais - leis e regras sociais - e o território. Nesse sentido, o fortalecimento da legislação e das instituições participativas é um dos requisitos para se avançar na efetivação da cidadania.

De acordo com Souza (s.d, s.p), a participação popular contribui sim para a eficiência das políticas pú- blicas. Por meio dela, é possível aumentar o controle da sociedade civil sobre os políticos profissionais, combater e enfraquecer as práticas clientelistas, romper com o monopólio decisório nas mãos das elites, reduzir as disparidades de infraestrutura, bem como elevar o nível de consciência da população sobre seus direitos. O mesmo autor atenta, ainda, para o fato de haver administraçóes municipais mais permeáveis à inserçấo da sociedade civil organizada nos processos decisórios governamentais do que outras.

As próximas seções e subseçōes deste estudo se destinam a apresentar algumas das particularidades do recorte de pesquisa e a pensar se há um padrão progressista ou não de gestão pública local.

\section{SOTEROPÓLIS: PARTICULARIDADES DO ESPAÇO POLÍTICO LOCAL}

Feita a apresentação da problemática em questâo deste trabalho, faz-se necessário destacar algumas das particularidades do recorte espacial da pesquisa. Isso vai contribuir para a compreensão da dimensão participativa, da democracia brasileira, no planejamento e na gestáo de políticas públicas no contexto local. Consideram-se, via de regra, renda e educaçáo importantes indicadores da existência de consciência cidadã.

Para Carvalho (2014, p.17), com base na afirmação de T. A. Marshall de que a educação popular possibilitou que os indivíduos desenvolvessem a consciência cidadã e passassem a lutar pelos seus direitos, "a ausência de uma população educada tem sido sempre um dos principais obstáculos à construção da cidadania civil e política”. Ainda segundo Carvalho, tanto a elevação da educaçáo quanto da renda indica aumento de expectativas e da consciência cidadá, vista pelo pesquisador como a "percepção mais clara e ampla de direitos" (p. 11). Além da renda e da educação, outros indicadores e particularidades serão tratadas a seguir.

Salvador, município sede do estado da Bahia, Brasil, é o terceiro maior do país em número total de habitantes, atrás apenas de São Paulo e Rio de Janeiro, primeiro e segundo lugar, respectivamente. Do total de 2.675.656 da população residente em Salvador, $2.674,923$ habitam na sede municipal, o que corresponde a um percentual de 99,97\% da população, e indica que Salvador é um município urbano, que abriga a terceira maior metrópole do país.

Em estudo divulgado pelo IBGE (2013), Salvador é listado entre os 100 maiores Produtos Internos Brutos - PIBs do Brasil. O município ocupa a $12^{\circ}$ posição, com um total de 38.819.520. Porém, 
no ranking do Índice de Desenvolvimento Humano Municipal (IDHM) de 2013, divulgado pelo Programa das Naçóes Unidas para o Desenvolvimento (PNUD), o terceiro maior município do país, Salvador, ocupa a $383^{\circ}$ posição entre os 5.565 municípios brasileiros, com IDHM de 0, 759 .

Apesar de se enquadrar com um IDHM considerado alto, acima do da média nacional $(0,744)$, Salvador apresenta graves e históricos problemas sociais, que se projetam na paisagem urbana do município. Sua organização espacial revela uma enorme disparidade na atuação das sucessivas administraçôes municipais ou a incompetência e incapacidade delas na condução do ordenamento espacial, como no caso do provimento de infraestrutura urbana à cidade.

O município sede da primeira capital do país passou, a partir da década de 1960 , por um acelerado processo de urbanizaçáo e intenso fenômeno de metropolizaçáo do seu aglomerado urbano, o que faz de Salvador a terceira maior metrópole do país. Metrópole que apresenta um quadro de carências acumuladas, de um lado, desequilíbrios espaciais tanto nos padróes de urbanização quanto de ocupação do solo, além de deficiências na oferta de serviços urbanos e, por outro, áreas desassistidas pelo poder executivo municipal.

O perfil do município de Salvador (ATLAS BRASIL, 2013) revela alguns indicadores socioeconômicos e demográficos. No que tange à renda, o estudo mostra que o Índice de Gini é 0,63 para o ano de 2010. A razão entre os rendimentos que associa renda à cor/raça indica que, no local com a maior população negra fora da África, os brancos ganham três vezes mais do que pretos e duas vezes mais do que pardos (IBGE, 2010).

Esses indicadores reforçam a constatação de Silva (2013), ao considerar que as desigualdades sociais presentes em Salvador não são apenas permeadas pelo fator econômico, mas também pelo fator racial. Nesse contexto, esse último fator assume relevante importância na realidade tratada, caracterizada por um quadro de profundas discrepâncias sociais, extrema concentração de renda e de criação de uma paisagem urbana marcada por grandes contrastes.

Problemas como esses só se agravam num contexto em que prevalece a prática do tratamento discricionário a diferentes áreas e bairros do município. Esse modelo de gestão municipal suscitou a emergência de inúmeros movimentos sociais. Estes movimentos, de modo muito ativo, passaram a contestar a ordem estabelecida de exclusão de grande parcela da população local, especialmente no que concerne ao acesso a serviços públicos primordiais para a dignidade humana.

A urbanizaçáo desigual, associada ao crescente processo de pauperização e espoliaçáo urbana, característicos do século XX, suscitou lutas organizadas e a ação coletiva de amplos setores da populaçáo, bem como a consolidação de importantes movimentos sociais, muitos deles surgidos nas décadas de 1940/1950.

Essa intensa mobilização ajudou a forjar um novo quadro político-administrativo, cujo marco maior foi o fortalecimento da escala municipal e do governo local. Tudo isso, aliado ao processo acelerado de urbanizaçáo pelo qual passou Salvador, ampliou as demandas sociais da população por bens e serviços públicos, "impondo novos desafios aos municípios, que passam a se constituir em 'locus' privilegiados para a implementação de políticas e para o encontro de soluçôes possíveis de desenvolvimento" (IVO, 1997, p.108).

É nesse contexto que se situa a ação dos movimentos sociais na busca por maior equidade e justiça socioespacial. Uma das condiçóes essenciais para que isso ocorra reside na efetiva democratização da gestão municipal e das decisóes governamentais, por meio de canais e arenas de participação da populaçáo local, que possibilitem a cooperação e a negociação entre sociedade civil e o poder executivo, a exemplo dos Conselhos Municipais.

\subsection{Institucionalização da participaçáo social em Salvador}

O processo de institucionalização da participação da sociedade civil na administração municipal de Salvador, bem como em outros municípios do país, está vinculado às lutas e pressóes de diversos movimentos sociais junto ao poder público local.

Em 1975 foi criado o primeiro Conselho Municipal de Políticas Públicas, o Conselho de Desenvolvimento Urbano (Condurb), de caráter consultivo. Todavia, a institucionalização da participação social em Salvador só ganhou fôlego a partir de 1990, acredita-se que muito graças "à induçáo do governo federal, que condicionou a transferência de recursos financeiros federais para os níveis subnacionais de governo à constituição desses fóruns, entre outros requisitos"(CORTES, 2011, p.79).

Embora as mobilizaçôes sociais remontem à década de 1970, só a partir de 1986, após a retomada de eleiçôes livres para o executivo municipal das capitais (em 1985), o discurso participativo e da descentralização passou a fazer parte da agenda do governo local (FERNANDES, 2003).

Em resposta às demandas por participação social 
na gestáo municipal, o governo de Salvador empreendeu um processo de divisão do território municipal em zonas administrativas, que consistiu, na prática, em dividir o território em administraçôes regionais compostas por "administradores e conselhos regionais de cidadáos, com poder de negociação junto ao executivo municipal, no estabelecimento de prioridades de ação nos bairros, tais como obras de infraestrutura, habitação popular e prestação de serviços públicos" (FERNANDES, 2003, p. 146).

Passadas mais de duas décadas da promulgação da CF/1988 e do grande avanço jurídico-legal, que o conjunto de inovaçóes institucionais significou para o país, em termos de garantias da participação política no planejamento e na gestão políticas públicas, a análise do fenômeno participativo em Salvador revela a existência de 36 Conselhos Municipais, Quadro 3, que integram a estrutura administrativa municipal.
$\mathrm{Na}$ contramão do que já ocorre há anos em alguns municípios brasileiros, em Salvador ainda não houve a implantação do Orçamento Participativo - importante arena de participação direta da população na definição de demandas prioritárias para a aplicação do orçamento público municipal. Nos últimos anos, houve avanços em determinadas políticas, mas o retrocesso e a timidez são as marcas mais expressivas das administraçóes que se sucederam.

Apesar de as Conferências temáticas serem uma realidade na capital baiana e dos avanços alcançados na criação de espaços participativos dedicados às políticas públicas e de segmentos especiais, a exemplo do Conselho de Assistência Social, Conselho do Idoso e Conselho da Pessoa com Deficiência, a inclusão da participação social na gestão das macropolíticas, a exemplo daquelas de desenvolvimento urbano, dá indícios de estagnação.

Quadro 3 - Conselhos Municipais institucionalizados em Salvador - 2015

\begin{tabular}{|l|c|}
\hline \multicolumn{1}{|c|}{ CONSELHO } & ANO DE \\
CRIAÇÃO \\
\hline $\begin{array}{l}\text { Conselho Municipal do Turismo - COMTUR } \\
\text { [Órgão ligado à Secretaria Municipal do Desenvolvimento, Turismo e Cultura] }\end{array}$ & 1964 \\
\hline $\begin{array}{l}\text { Conselho Municipal de Tributos - CMT[ } \\
\text { Órgáo ligado à Secretaria Municipal da Fazenda. Não funciona como os demais Conselhos de Políticas] }\end{array}$ & 1966 \\
\hline $\begin{array}{l}\text { Conselho de Procuradores - CP } \\
\text { [Órgão ligado à administração direta - gabinete do prefeito] }\end{array}$ & 1968 \\
\hline $\begin{array}{l}\text { Conselho Municipal de Desenvolvimento Urbano - CONDURB } \\
\text { [Órgão ligado à Secretaria Municipal de Urbanismo e Transporte] }\end{array}$ & 1975 \\
\hline $\begin{array}{l}\text { Conselho Municipal de Educaçáo - CME } \\
\text { [Órgão ligado à Secretaria Municipal de Educação] }\end{array}$ & 1981 \\
\hline $\begin{array}{l}\text { Conselho Municipal da Mulher - CMM } \\
\text { [Órgão ligado à administraçáo direta - gabinete do prefeito] }\end{array}$ & 1985 \\
\hline $\begin{array}{l}\text { Conselho Municipal de Meio Ambiente - COMAM } \\
\text { [Órgão ligado à Secretaria Cidade Sustentável] }\end{array}$ & 1986 \\
\hline $\begin{array}{l}\text { Conselho Municipal dos Direitos da Pessoa com Deficiência - COMPED } \\
\text { [Órgáo ligado à Secretaria Municipal de Promoção Social e Combate à Pobreza] }\end{array}$ & 1987 \\
\hline $\begin{array}{l}\text { Conselho Municipal das Comunidades Negras - CMNC } \\
\text { [Órgăo ligado à Secretaria Municipal de Reparação] }\end{array}$ & 1990 \\
\hline $\begin{array}{l}\text { Conselho Municipal de Atençáo ao Consumo de Substâncias Psicoativas - CMACSP } \\
\text { [Órgão ligado à Secretaria Municipal de Saúde] }\end{array}$ & 1990 \\
\hline $\begin{array}{l}\text { Conselho Municipal de Saúde do Salvador - CMSSSA } \\
\text { [Órgão ligado à Secretaria Municipal de Saúde] }\end{array}$ & 1990 \\
\hline
\end{tabular}

(Continua...) 
Quadro 3 - Continuação...

\begin{tabular}{|c|c|}
\hline CONSELHO & $\begin{array}{l}\text { ANO DE } \\
\text { CRIAÇÃO }\end{array}$ \\
\hline $\begin{array}{l}\text { Conselho Municipal do Carnaval e Outras Festas Populares - COMCAR } \\
\text { [Órgáo ligado à Secretaria Municipal do Desenvolvimento, Turismo e Cultura] }\end{array}$ & 1990 \\
\hline $\begin{array}{l}\text { Conselho Municipal dos Direitos da Criança e do Adolescente - CMDCA } \\
\text { [Órgáo ligado à Secretaria Municipal de Promoção Social e Combate à Pobreza] }\end{array}$ & 1990 \\
\hline $\begin{array}{l}\text { Conselho Municipal de Direitos Humanos, Cidadania e Defesa Social - CMDHCD } \\
\text { [Órgáo ligado à Secretaria Municipal de Promoçáo Social e Combate à Pobreza] }\end{array}$ & 1991 \\
\hline $\begin{array}{l}\text { Conselho Municipal de Proteção e Defesa do Consumidor - CMPDC } \\
\text { [Órgáo ligado à Secretaria Municipal de Ordem Pública] }\end{array}$ & 1992 \\
\hline $\begin{array}{l}\text { Conselho Municipal do Idoso - CMI } \\
\text { [Órgáo ligado à Secretaria Municipal de Promoção Social e Combate à Pobreza] }\end{array}$ & 1992 \\
\hline $\begin{array}{l}\text { Conselho Municipal de Esporte e Lazer - COMEL } \\
\text { [Órgão ligado à Secretaria Municipal de Educação] }\end{array}$ & 1994 \\
\hline $\begin{array}{l}\text { Conselhos Escolares das Unidades Escolares da Rede Pública Municipal } \\
\text { [ Órgáo ligado à Secretaria Municipal de Educaçáo] }\end{array}$ & 1994 \\
\hline $\begin{array}{l}\text { Conselho Municipal de Transporte - CMT } \\
\text { [Órgáo ligado à Secretaria Municipal de Urbanismo e Transporte] }\end{array}$ & 1995 \\
\hline Conselhos Locais de Saúde - CLS & 1995 \\
\hline $\begin{array}{l}\text { Conselho Municipal de Assistência Social - CMAS[ } \\
\text { Órgáo ligado à Secretaria Municipal de Promoçáo Social e Combate à Pobreza] }\end{array}$ & 1996 \\
\hline $\begin{array}{l}\text { Conselho Municipal de Defesa Civil - CMDC } \\
\text { [Órgáo ligado à Secretaria Municipal de Infraestrutura e Defesa Civil] }\end{array}$ & 1996 \\
\hline $\begin{array}{l}\text { Conselho Municipal de Alimentação Escolar - COMAE } \\
\text { [Órgáo ligado à Secretaria Municipal de Educação] }\end{array}$ & 1997 \\
\hline $\begin{array}{l}\text { Conselho Municipal de Cultura - CMC } \\
\text { [Órgáo ligado à Secretaria Municipal do Desenvolvimento, Turismo e Cultura] }\end{array}$ & 1997 \\
\hline $\begin{array}{l}\text { Conselho Municipal de Acompanhamento e Controle Social do Fundo de dos Profissionais da Educação - } \\
\text { CMACSFUN } \\
\text { [Órgão ligado à Secretaria Municipal de Educação] }\end{array}$ & 1998 \\
\hline Manutenção e Desenvolvimento da Educação Básica e de Valorização Conselhos Distritais de Saúde - CDS & 1998 \\
\hline $\begin{array}{l}\text { Conselho Gestor do Fundo Municipal de Habitação - CGFMH } \\
\text { [Secretaria Municipal de Infraestrutura e Defesa Civil] }\end{array}$ & 2002 \\
\hline $\begin{array}{l}\text { Conselho Municipal de Acompanhamento da Aplicação dos Recursos Recebidos do Fundo de Investimento } \\
\text { Econômico e Social da Bahia - FIES } \\
\text { [Órgáo ligado à Secretaria Municipal da Fazenda. Não funciona como os demais Conselhos de Políticas] }\end{array}$ & 2003 \\
\hline $\begin{array}{l}\text { Conselho de Desenvolvimento Econômico e da Inovação do Salvador - CDEIS } \\
\text { [Órgáo ligado à Secretaria Municipal do Desenvolvimento, Turismo e Cultura] }\end{array}$ & 2004 \\
\hline $\begin{array}{l}\text { Conselho Municipal de Relaçóes Internacionais - CMRI } \\
\text { [Órgão ligado à Secretaria Municipal do Desenvolvimento, Turismo e Cultura, mas não funciona como os } \\
\text { demais Conselhos] }\end{array}$ & 2004 \\
\hline
\end{tabular}

(Continua...)

Geografia, Ensino \& Pesquisa, Vol. 21 (2017), n.3, p. 8-24

ISSN: 2236-4994 DOI: $10.5902 / 2236499425524$ 
Quadro 3 - Continuação...

\begin{tabular}{|l|c|}
\hline \multicolumn{1}{|c|}{ CONSELHO } & $\begin{array}{c}\text { ANO DE } \\
\text { CRIAÇÃO }\end{array}$ \\
\hline $\begin{array}{l}\text { Conselho Municipal de Segurança Alimentar e Nutricional de Salvador - COMSEA } \\
\text { [Órgáo ligado à Secretaria Municipal de Promoção Social e Combate à Pobreza] }\end{array}$ & 2004 \\
\hline $\begin{array}{l}\text { Conselho Municipal de Trabalho, Emprego e Geraçáo de Renda - CMTEGR } \\
\text { [Órgão ligado à Secretaria Municipal do Desenvolvimento, Turismo e Cultura] }\end{array}$ & 2004 \\
\hline $\begin{array}{l}\text { Conselho Deliberativo do Fundo Municipal para o Desenvolvimento Humano e Inclusão Educacional de } \\
\text { Mulheres Afrodescendentes - CODF } \\
\text { [Órgáo ligado à Secretaria Municipal de Educaçáo. Não funciona como os demais Conselhos de Políticas] }\end{array}$ & 2005 \\
\hline $\begin{array}{l}\text { Conselho Gestor do Programa de Parcerias Público Privadas do Município do Salvador - CGP } \\
\text { [Órgáo ligado à Casa Civil] }\end{array}$ & 2006 \\
\hline $\begin{array}{l}\text { Conselho Municipal do Salvador - CMS } \\
\text { [Órgáo ligado à Secretaria Municipal de Urbanismo e Transporte] }\end{array}$ & 2008 \\
\hline $\begin{array}{l}\text { Conselho Gestor do Fundo Municipal de Saneamento Básico - CFMSB } \\
\text { [Órgáo ligado à Secretaria Municipal de Infraestrutura e Defesa Civil, mas não funciona como os demais } \\
\text { Conselhos Municipais] }\end{array}$ & 2011 \\
\hline $\begin{array}{l}\text { Conselho Gestor do Parque das Dunas } \\
\text { [Órgáo ligado à Secretaria Cidade Sustentável] }\end{array}$ & 2011 \\
\hline $\begin{array}{l}\text { Conselho Gestor de Concessóes - CGC } \\
\text { [Órgão ligado à Casa Civil. Não funciona como os demais Conselhos de Políticas] }\end{array}$ & 2013 \\
\hline
\end{tabular}

Fonte: <http://www.salvador.ba.gov.br/index.php/2-uncategorised/42-iframe-cadastro-organizacional>.

\subsection{Pela democratizaçáo do poder e do espaço ur- bano}

É estranho perceber que a inclusão da participação popular e o acolhimento, pela gestão municipal, das demandas sociais são extremamente problemáticos e pouco relevantes logo na área das políticas urbanas e de infraestrutura e nos setores mais problemáticos e deficientes, em termos de oferta equitativa de serviços de qualidade à maior parte da população.

Município sede da primeira região metropolitana da Bahia, Salvador apresenta graves problemas de infraestrutura, que se associam ao caótico processo de urbanização - suburbanização - pelo qual passou nos últimos anos.

Sobrecarga de infraestrutura instalada, déficit habitacional, submoradias, periferização, favelização, precária mobilidade e acessibilidade urbana, déficit de equipamentos e de oferta de serviços públicos em bairros periféricos (SERPA, 2007) são exemplos da consequência desse processo, que tem comprometido o gozo pleno dos direitos de uma grande parte de seus cidadãos.
O déficit de infraestrutura e os diversos problemas urbanos, entre outras faces dessa suburbanizaçáo, são reveladores do quáo distante os moradores soteropolitanos têm vivido do ideário de realização da reforma urbana, por meio de uma ampla participaçáo popular, preconizada tanto pela Constituiçấo quanto pelo Estatuto da Cidade.

Em Salvador, apesar da relevância conferida pelo Estatuto da Cidade à participaçáo popular no planejamento e na gestão das políticas públicas urbanas, aquele que deveria ser o principal espaço participativo para negociação entre a sociedade civil organizada e a administração municipal sobre as questôes de interesse público, o Condurb, encena aquilo que Souza (s.d, s.p) denomina como uma participação fraca ou pseudoparticipação.

No campo das políticas urbanas, a situação dos Conselhos de infraestrutura, a exemplo do Conselho Municipal de Transportes (CMT), criado em 1996, e do Conselho Municipal de Meio Ambiente (COMAM), criado em 1986, revela-se mais problemática, visto que seu exercício já foi interrompido por mais de um ano 
devido a decisôes arbitrárias dos gestores municipais quanto ao ordenamento do solo urbano do município.

Um balanço deve ser feito sobre a dinâmica de interaçáo entre sociedade e Estado/governo, levando em conta o modo como se relacionam, no sentido de avaliar e qualificar os modos de diálogo e o processo de democratização da gestâo, a exemplo do que propóem Azevedo e Prates (1991). Os autores desenvolveram duas concepçôes de interação: a Participação Restrita participação na escala micro, e a Participação Ampliada - participação na escala macro.

A "Participação Restrita" ou a participação em escala micro refere-se:

[ao] envolvimento da comunidade diretamente beneficiada em um projeto específico, ou em um programa de âmbito local, através de fornecimento de máo de obra (voluntária ou sub-remunerada), e em definições de microprioridades e alocações de certos recursos e equipamentos de consumo coletivo, diretamente concernentes àquela iniciativa governamental específica (AZEVEDO; PRATES, 1991, p. 135)

E a "Participação Ampliada" ou a participação em escala macro se caracteriza pela:

[...] capacidade dos grupos de interesse de influenciar, direta ou indiretamente, as macroprioridades, as diretrizes e a formulação, reestruturação ou implementação de programas e políticas públicas (AZEVEDO; PRATES, 1991, p. 136)

Ao basear-se nessa concepção de interação, chega-se à conclusão de que o fenômeno da participação social nos Conselhos Municipais em Salvador, pelo menos no campo das políticas urbanas, se situa aquém de uma Participação Ampliada - participação na escala macro.

\section{A PARTICIPAÇÁO SOCIAL EM SALVA- DOR: CONSELHOOS DE ASSISTÊNCIA SO- CIAL, DO IDOSO E CONSELHO DE SAÚDE.}

Muito embora em Salvador haja condiçóes legais reais de participação social institucionalizada (recursos institucionais, como os Conselhos Municipais), verifica-se que, de modo geral, a população local e os movimentos e entidades sociais não se apropriam efetivamente desses espaços. Afinal, muito deles ainda não estão em exercício e isso se deve, também, à não abertura e simpatia política dos gestores com a prática de compartilhamento do poder de decisão.

O diagnóstico que se faz, com base na análise da institucionalização e da atuação dos Conselhos de infraestrutura ou recursos naturais (já mencionada anteriormente), é que há, no município, uma timidez maior no desenvolvimento de práticas participativas instituciona- lizadas nas áreas de transportes, acessibilidade e mobilidade, habitação e meio ambiente.

Justamente no campo das políticas públicas capazes de impactar, de modo mais profundo, a infraestrutura do município como um todo e, por sua vez, modificar o cotidiano da populaçáo, é que se vê que a queda de braço entre sociedade civil organizada e poder público local é mais difícil, afinal, em vários momentos, as duas últimas administraçóes municipais tomaram iniciativas contrárias à participação social no planejamento e na gestão urbano municipais.

Constatou-se que, na área de garantia de direitos, representada pelo Conselho Municipal do Idoso, mesmo com as queixas de seus integrantes (quanto à falta de atenção por parte da gestão municipal), a mobilização e o engajamento dos integrantes no segmento foram os maiores, tendo feito e fazendo grande diferença na hora de pressionar o poder executivo quanto à conquista e à garantia de direitos.

Em relação ao CMAS, ele tem uma dinâmica bem compatível com aquilo que se espera de um Conselho. Nas assembleias ordinárias e extraordinárias, das quais participou, constatou-se que a defesa e a proteção social de grupos socialmente vulneráveis eram cumpridas e que as deliberaçóes eram democraticamente consensuadas no interior do Conselho, e, em sua maior parte, acatadas pela administração local.

No que tange à atuação do Conselho Municipal de Saúde, chegou-se à conclusão de que ele cumpre satisfatoriamente as finalidades identificadas no regimento do Conselho. Percebeu-se, com respaldo nas reuniōes, que o CMS é deliberativo e atua na fiscalização e no controle do uso e da aplicação dos recursos do Fundo Municipal de Saúde.

Entre os três Conselhos analisados mais de perto, o CMS é o único tripartite, ou seja, acolhe o setor produtivo (empresarial), prestadores de serviços privados. Observou-se que as discussóes no CMS eram muito mais calorosas e que os ânimos dos participantes se exaltavam com mais facilidade, talvez, devido à pluralidade de interesses representados. Isso leva a crer que o fenômeno que deve caracterizar um espaço da democracia se fez presente no Conselho de Saúde, isto é, o conflito de ideias mediado pela política.

Tanto no caso do CMAS quanto do CMS, pesam a favor o fato de existir um fundo municipal de Assistência Social e de Saúde, respectivamente. A existência do fundo, aliada ao caráter deliberativo, possibilita que o Conselho possa fazer pressão junto ao poder público para que as políticas sejam implementadas da maneira 
mais democrática possível. O fundo garante recursos para que os Conselhos possam desenvolver atividades, a exemplo da realização de conferências, que se constituem em importantes ambientes de escuta, de levantamento de demandas e de soluçóes.

Todos os três Conselhos Municipais avaliados têm a competência de fiscalizar e deliberar sobre suas políticas; já em relaçáo à composição e à organização, os Conselhos, estudos de casos, são paritários. O desenho institucional, como revelaram Brasil et al. (2013), é um elemento fundamental que pode favorecer ou não a qualidade dos processos participativos e deliberativos, como também pode incidir sobre a capacidade decisória e o funcionamento desses canais.

Em relação ao caráter deliberativo, concorda-se com Machado (2009, p. 40) que "[o poder deliberativo] é uma importante conquista, que fortalece seu processo participativo, tendo cada grupo de indivíduos igual influência na decisão final". Contudo, o fato de o Conselho deliberar náo significa que a administração municipal irá acatar as decisóes tomadas por meio do consenso próprio do jogo político democrático.

De um modo geral, observa-se que, em Salvador, é no campo das políticas públicas, sociais ou de direitos que os Conselhos Municipais são mais efetivos, em comparação aos Conselhos das áreas de infraestrutura e recursos naturais.

\section{CONSIDERAÇÓES FINAIS}

Uma primeira consideração que merece ser feita a respeito das percepçóes e descobertas, provenientes da investigaçáo teórica e do trabalho empírico, que sustentaram esta pesquisa, é que o paradigma participativo é hoje uma prática, isto é, uma realidade social concreta nos municípios brasileiros.

Todavia, o sucesso e, ao mesmo tempo, o náo êxito, seja na institucionalização desses ambientes de representação e participação social ou na atuação de alguns Conselhos Municipais, integram essa mesma realidade.

Sem sombra de dúvida, o exercício dos Conselhos Municipais tem implicaçóes espaciais, como mostram Lima e Bitoun (2004). Borges (2015) faz uma discussão minimamente interessante em que mostra por que razão a Democracia interessa à Geografia e por que a participação social é também um problema geográfico. Práticas sociais (deliberações e materialização de decisóes) gravitam em torno de Conselhos Municipais e atuam no (re) ordenamento municipal e, portanto, na organização dos espaços políticos locais.

Não se deve cair no equívoco de qualificar esses espaços, segundo casos específicos, como ineficientes, inoperantes, ou mesmo afirmar que os Conselhos são manipulados pelo poder público local e que, portanto, encenam uma trama de simples faz de conta de representação dos anseios da população local.

Tendo ciência da variedade de espaços políticos, com características mais diversas e plurais, qualquer opiniâo, cujas conclusóes sejam gerais e universais, especialmente no caso da efetividade de Conselhos Municipais no Brasil, com base em análises que tenham como suporte um único estudo de caso, ou que por meio delas emitam pareceres radicalmente pessimistas quanto à eficácia desses espaços participativos e vice-versa, soa frágil.

Também, qualquer consideração que seja totalmente romântica ou incrédula quanto ao sentido e ao cumprimento da prática participativa, por meio dos Conselhos Municipais, pode ser considerada desprovida de senso crítico ou composta por um pessimismo radical.

A institucionalização e a regulamentação da participação social foram e são, de fato, uma grande conquista para toda a sociedade brasileira, principalmente em termos de democratizaçáo das políticas públicas e sociais.

Porém, o que alguns trabalhos revelaram, e que também se constatou no recorte desta investigação, é que a apropriação desses espaços político-participativos pela sociedade civil deve fazer toda a diferença, especialmente, em contextos muito contrários à participação.

É de conhecimento que, no país, a mobilização de segmentos sociais demandou a ampliação da participação social, o que possibilitou a inscrição de diretrizes constitucionais de participação social em relação a diversos setores de políticas públicas. Desse modo, a efetividade e a eficácia da atuação dos Conselhos Municipais dependem muito mais da permanente vigilância, do engajamento e da ação política coletiva da sociedade civil local.

Os ganhos de participaçáo, em termos de criação legal de uma institucionalidade participativa, são reais tanto no Brasil (com mais de 43 mil Conselhos) quanto em Salvador, com os mais variados tipos de Conselhos nas mais diversas áreas de políticas públicas e setoriais.

Apesar de todo o entusiasmo, fascinação e expectativas de avanços no processo democrático brasileiro, que giram em torno do paradigma participativo e das instituiçóes participativas, de todas as conquistas, dos instrumentos jurídico-normativos que garantem o direito à participação política da sociedade civil no planejamento e gestão de políticas, os resultados deste estudo 
empírico permitem considerar que um dos grandes desafios a ser superado pela sociedade civil organizada diz respeito à eliminação da herança cultural, política e administrativa conservadora, assistencialista, mandatária e centralizadora, ainda existente em muitos dos municípios brasileiros.

Mesmo após o Brasil ter se tornado uma referência na garantia da participação social, é importante frisar que a lei por si só não promoverá a efetivação de maior igualdade e equidade socioespacial, sendo necessária uma elevação do grau de organização e mobilização da sociedade civil.

Esta elevação e esta mobilização têm o desafio permanente de (re)instituir um projeto municipal de democratização de decisões governamentais. A superação da apatia política, o resgate do ideal de transformação social, a formação de uma nova consciência democrática e a recriação de uma cultura política participativa se impóem ao aprimoramento da prática conselheirista e à efetividade da participação social.

Por tudo isso, é preciso assinalar que esses desafios são os combustíveis para o rompimento do padrão tecnoburocrático e da aversão dos governos locais à incorporação da participação da sociedade civil nos processos de planejamento e gestáo das políticas municipais.

\section{REFERÊNCIAS}

ATLASBRASIL. Ranking IDHM Municípios 2010. Disponível em: <http://www.pnud.org.br/atlas/ranking/ Ranking-IDHM-Municipios-2010.aspx>. Acessado em 30 de setembro de 2014.

AVRITZER, L. A Qualidade da democracia e a questão da efetividade da participação: mapeando o debate. In: Roberto Rocha C. Pires. (Org.). Efetividade das instituiçôes participativas no Brasil: estratégias de avaliação. Brasilia: IPEA, 2011, v. 7 (372 p.).

BARBOSA, J. Luiz. Política pública, gestáo municipal e participação social na construção de uma agenda de direitos à cidade. Scripta Nova. Revista Eletónica de Geografía y Ciencias Sociais. vol XIV, n. 331 (51), 1, 2010.

BLÄSER, R; SOYER, D. Organisations non-gouvernementales transnationales et géographie - perspectives d'outre-Rhin. Annales de Géographie, nº68, p. 359-381, 2009.

BORGES, S. Espaços políticos participativos: caminhos e descaminhos da participaçáo social nos Conselhos Municipais em Salvador, Bahia. 2015. 138 f. Dissertação (Mestrado em Geografia) - Programa de Pós-Graduaçáo em Geografia, Universidade Federal da Bahia, Salvador, 2015a. Institucionalização da participação social e demo- cratização da política urbana em Salvador-Bahia: o caso dos conselhos municipais. In: Rui Jacinto; Valentin Cabero Diéguez. (Org.). Espaços de Fronteira, Territórios de Esperança. 1. ed.Lisboa: Ancora, 2015, v. , p. 143-155.

Inovaçóes democráticas no Brasil: os conselhos municipais de políticas e os papéis da sociedade civil na gestão local. In: Anais do $1^{\circ}$ Congresso Brasileiro de Geografia Política, Geopolítica e Gestão do Território, 2014, Rio de Janeiro.

BRASIL, F. de Paula D et al. Participação, desenho institucional e alcances democráticos: uma análise do Conselho das Cidades (ConCidades). Revista de Sociologia e Política (UFPR. Impresso), v. 21, p. 5-18, 2013.

BUSSI, Michel. Geógraphie, démocratie et participation: explication d'une distance, arguments pour un rapprochement. Géocarrefour, 76 (3), 2001. p. 265-272. Disponível em: <http://www.persee.fr/web/revues/home/prescript/ article/geoca_1627-4873_2001_num_76_3_2564>. Acessado em 19 de Junho de 2012.

.Pour une approche comparative des élections. Espace, populations, sociétés, v.3, n.1, 2003. Disponível em: <http://www.persee.fr/web/revues/home/prescript/article/ espos_0755-7809_2003_num_21_3_2095>. Acessado em 15 de Julho de 2014.

. Pour une géographie de la démocratie. L'Espace Politique, v. 1, n. 1, 2007a. Disponível em: $<\underline{\text { http://espa- }}$ cepolitique.revues.org/index $243 . \mathrm{html}>$. Acesso em: 29 de Junho de 2014.

Repenser les territoires ensemble: une inflexion paradigmatique pour la géographie politique? L'Espace Politique, v. 3, n. 3, 2007b. Disponível em: <http://espacepolitique.revues.org/648>. Acessado em 29 de Junho de 2014.

BUVINICH, D. P. R. O mapeamento da institucionalizaçáo dos conselhos gestores de políticas no Brasil. Revista de Administraçáo Pública, Rio de Janeiro, n.48, v.1.p.55-82, jan./fev. 2014.

CARVALHO, J. M. Cidadania no Brasil: o longo caminho. $18^{a}$ ed. Rio de Janeiro: Civilizaçáo Brasileira, 2014. v. $1.254 \mathrm{p}$.

Democratização e cultura política de massas no Brasil. Revista Lua Nova, nº.26, São Paulo, Aug. 1992.

CASTRO, I. E. A democracia como um problema para a geografia: o fundamento territorial da política. In: CASTRO, I.E.; RODRIGUES, J.N.; RIBEIRO, R.W. (Org.). Espaços da Democracia: para a agenda da Geografia Política Contemporânea. 1. ed.Rio de Janeiro: Bertrand Brasil, 2013 , v. 1 , p. $15-40$.

; RODRIGUES, J.N.; RIBEIRO, R. W. Para o encontro da geografia com a democracia. In: CASTRO, I.E.; 
RODRIGUES, J.N.; RIBEIRO, R.W. (Org.). Espaços da Democracia: para a agenda da Geografia Política Contemporânea. 1. ed.Rio de Janeiro: Bertrand Brasil, 2013, v. 01, p. 09-18.

Geografia e política: território, escalas de ação e instituiçóes. 3. ed. Rio de Janeiro: Bertrand Brasil, 2010. $299 \mathrm{p}$.

O espaço político local como condição de construção (mas também de negaçáo) da democracia. In: José Borzachiello da Silva; Luiz Cruz Lima; Denise Elias. (Org.). Panorama da geografia brasileira. 1.ed.São Paulo: ANNABLUME, 2006, v. 1, p. 49-63.

O município brasileiro em debate. Algumas questóes sobre diferenças territoriais e participação - Publicação em Site do Instituto de Economia da Universidade Federal do Rio de Janeiro. 2004. Disponível em: <http://www. ie.ufri.br/aparte/pdfs/inacastro o municipio em debate. pdf $>$. Acessado em 29 de Junho de 2014.

O problema da espacialidade da democracia e a ampliação da agenda da geografia brasileira. Revista da ANPEGE, v. 7, p. 291-305, 2011.

Instituiçóes e território. Possibilidades e limites ao exercício da cidadania. Geosul, v.18, n.36, 2003.

CORTES, S. M. V. Instituiçóes participativas e acesso a serviços públicos nos municípios Brasileiros. In: Roberto Rocha C. Pires. (Org.). Efetividade das instituiçóes participativas no Brasil: estratégias de avaliação. Brasília: IPEA, 2011, v. p. 77-86.

FERNANDES, A. Sérgio A. A trajetória de democratização da gestão municipal em Recife e Salvador: Escolhas Políticas e Processo Decisório. O\&S. Organizaçóes \& Sociedade, Salvador, v. 10, n.27, p. 141-160, 2003.

GOHN, M. G. M. Os Conselhos Municipais e a gestáo urbana. In: Luiz Cesar Ribeiro; Sergio Azevedo; Orlando Alves Santos Júnior. (Org.). Governança Democrática e Poder Local: a experiência dos conselhos municipais no Brasil. 1a ed.Rio de Janeiro: REVAN/FASE, 2004, v. 1, p. 57-93.

HERMET, Guy. As transiçôes democráticas no século XX: comparação entre América Latina e Leste Europeu. In: ABREU, Alzira Alves de (org.). Transiçóes em fragmentos: desafios da democracia no final do século XX. Rio de Janeiro: Editora FGV, 2001, p. 13-43.

HUNTINGTON, S. A terceira onda: a democratizaçáo no final do século XX. São Paulo: Ática, 1994.

IBGE (Instituto Brasileiro de Geografia e Estatística). Indicadores Sociais Municipais 2010: incidência de pobreza é maior nos municípios de porte médio. Disponível em: <http://www.censo2010. ibge.gov.br/noticias-censo?view=noticia Acessado em: 19 de Outubro de 2014.

IBGE, Censo Demográfico 2010. Disponível em: $<$ http://www.ibge.gov.br/home/estatistica/populacao/censo2010/educacao e deslocamento/default.shtm>. Acessado em: 23 de outubro de 2014.

LAVALLE, Adrian G. Participação: valor, utilidade, efeitos e causa. In: Roberto Rocha C. Pires. (Org.). Efetividade das instituições participativas no Brasil: estratégias de avaliação. Brasília: IPEA, 2011, v. 7 (372 p.).

LIMA, Rosa M, C. de; BITOUN, J. . Os Conselhos Municipais da Região Metropolitana do Recife: aspectos da cultura cívica. In: Orlando Alves dos Santos Junior; Luiz Cesar de Queiroz Ribeiro; Sergio Alves de Azevedo. (Org.). Governança democrática e poder local. 1. ed.Rio de Janeiro: Editora Revam, 2004, v. , p. 95-130.

LÜCHMANN, L. H. H. O desenho institucional dos conselhos gestores. In: RUBENS PINTO LYRA. (Org.). Participação e segurança pública no Brasil: teoria e prática. João Pessoa: Ed. UFPB, 2009, v., p. -390

MACHADO, Eloise H. H. Conselhos gestores e disposições políticas: um estudo de caso da região metropolitana de Curitiba. 2009. 100 f. Dissertação (Mestrado) - Curso de Pós-graduação em Sociologia, Departamento de Ciências Sociais, Universidade Federal do Paraná, Curitiba, 2009.

MAGDALENO, F. S. Lei e território em democracias político-representativas. In: CASTRO, I.E.; RODRIGUES, J.N.; RIBEIRO, R.W. (Org.). Espaços da Democracia: para a agenda da geografia política contemporânea. 1ed. Rio de Janeiro: Bertrand Brasil, Faperj, 360 p. 2013.

OFFE, Claus. A atual transição da história e algumas opções básicas para as instituições da sociedade. In: BRESSER PEREIRA, L. C.; WILHEIM, Jorge; SOLA, L. (Org.). Estado e sociedade em transformação. São Paulo: UNESP, 1999, p. 119145.

PLANALTO. Decreto $N^{\circ} 8.243$, de 23 de maio de 2014. Disponível em: <http://www.planalto.gov. br/ccivil 03/ Ato2011-2014/2014/Decreto/D8243. htm>.Acessado em: 10 de Março de 2015.

PUTNAM, R. D. Comunidade e democracia: a experiência da Itália moderna. Rio de Janeiro: Fundaçáo Getúlio Vargas, 1996.

RODRIGUES, J. N. Políticas públicas e geografia: retomad64de2Q14t debate. Geousp, São Paulo, v. 18, n. 1, p. 152- 
RÜCKERT, A. A. Reforma do Estado, reestruturaçóes territoriais, desenvolvimento e novas territorialidades. Geousp, São Paulo, v. 17, p. 79-94, 2005.

SERPA, A. S. P. Periferização e metropolização no Brasil e na Bahia: o exemplo de Salvador. GeoTextos, vol.3, n.1 e 2, p. 31-46, 2007.

SILVA, J. C. o poder público, a dinâmica da produção espacial e segregação racial na cidade de Salvador Bahia / Brasil. In: Anales 14' EGAL - Encuentro de Geóografos de América Latina, 2013, Lima - Perú.

SOLA, L. Reforma do Estado, para qual Democracia? O lugar da Política. In: BRESSER PEREIRA, L. C.; WILHEIM, Jorge; SOLA, L. (Org.). Estado e sociedade em transformaçăo. São Paulo: UNESP, 1999, v. 1, p. 23-65.

SOUZA, Marcelo Lopes de, A cidade, o seu Estatuto e a sua gestão "democrática". Disponível em: <http://www.geografia.ufrj.br/nuped/textos/acidadeoseuestatutogestao.pdf $>$. Acesso em: 03 de Julho de 2014.

A teorização sobre o desenvolvimento em uma época de fadiga teórica, ou: sobre a necessidade de uma "teoria aberta" do desenvolvimento sócio-espacial. Território, Rio de Janeiro, v. 1, n.1, p. 5-23, 1996.

WANIEZ, Philippe et al. Du local au national, la consolidation démocratique au Brésil. Espace, populations, sociétés,v.3, n.1, 2003. Disponível em: <http:// www.persee.fr/web/revues/home/prescript/article/espos 0755-7809 2003 num $2132102>$. Acessado em: 15 de Julho de 2014.

\section{Notas de fim}

1 Rückert (2005) chama atenção que, nos estudos de Geografia Política Clássica, o Estado era o principal agente político organizador do espaço. Segundo o autor, essa abordagem esteve sustentada em uma concepção unidimensional do poder, que minimizou ou sempre relativizou as implicações espaciais das práticas sociais de agentes políticos coletivos. No mesmo texto, atenta para a redemocratização recente do país, o processo de reforma do Estado, a descentralização e as reestruturações territoriais, além dos novos papéis desempenhados pela sociedade civil organizada na vida pública.

2 Com base em Holston (2013, p. 68) sobre as dimensões da cidadania - formal e substantiva.

3 Diante da discussão feita por Hermet (2001), sobre a existência de um duplo pressuposto metodológico e histórico - transitologia e consolidologia - para a análise de processos de transição de regimes políticos, (a respeito do processo de transição de regimes autoritários de governos para regimes democráticos),é preferível falar apenas em transição política.
4 Considera-se a equidade como um princípio fundamental para a formulação de políticas públicas e territoriais voltadas para reduzir ou minimizar desigualdades socioespaciais e, por sua vez, promover justiça social.

\section{Correspondência do autor:}

\author{
sergioborges \\ sergioborges25@gmail.com
}

ARTIGO RECEBIDO EM: 08/01/2017

REVISADO PELO AUTOR EM: 21/09/2017

ACEITO PARA PUBLICAÇÃO EM: 21/09/2017 